\title{
COVID-19 in ESRD and Acute Kidney Injury
}

\author{
Jeroen P. Kooman Frank M. van der Sande
}

Division of Nephrology, Department of Internal Medicine, Maastricht University Medical Centre, Maastricht, The Netherlands

\section{Keywords}

COVID-19 · Pathophysiology $\cdot$ Kidney $\cdot$ Dialysis

\begin{abstract}
The COVID-19 pandemic has greatly affected nephrology. Firstly, dialysis patients appear to be at increased risk for infection due to viral transmission next to an enhanced risk for mortality as compared to the general population, even in the face of an often apparently mild clinical presentation. Derangements in the innate and adaptive immune systems may be responsible for a reduced antiviral response, whereas chronic activation of the innate immune system and endothelial dysfunction provide a background for a more severe course. The presence of severe comorbidity, older age, and a reduction of organ reserve may lead to a rapid deterioration of the clinical situation of the patients in case of severe infection. Secondly, patients with COVID-19 are at increased risk of acute kidney injury (AKI), which is related to the severity of the clinical disease. The presence of AKI, and especially the need for renal replacement therapy (RRT), is associated with an increased risk of mortality. AKI in COVID-19 has a multifactorial origin, in which direct viral invasion of kidney cells, activation of the renin-angiotensin aldosterone sys-
\end{abstract}

karger@karger.com www.karger.com/bpu

Karger $\stackrel{\text { ' }}{=}$

GOPEN ACCESS
(C) 2020 The Author(s)

Published by S. Karger AG, Basel

This is an Open Access article licensed under the Creative Commons Attribution-NonCommercial-4.0 International License (CC BY-NC) (http://www.karger.com/Services/OpenAccessLicense), applicable to the online version of the article only. Usage and distribution for commercial purposes requires written permission. tem, a hyperinflammatory response, hypercoagulability, and nonspecific factors such as hypotension and hypoxemia may be involved. Apart from logistic challenges and the need for strict hygiene within units, treatment of patients with ESRD and COVID-19 is not different from that of the general population. Extracorporeal treatment of patients with AKI with RRT can be complicated by frequent filter clotting due to the hypercoagulable state, for which regional citrate coagulation provides a reasonable solution. Also, acute peritoneal dialysis may be a reasonable option in these patients. Whether adjuncts to extracorporeal therapies, such as hemoadsorption, provide additional benefits in the case of severely ill COVID-19 patients needs to be addressed in controlled studies.

(c) 2020 The Author(s) Published by S. Karger AG, Basel

\section{Introduction}

Infections with severe acute respiratory syndrome coronavirus 2 (SARS-CoV-2), an enveloped RNA betacoronavirus, first identified at the end of 2019 in Wuhan, have rapidly turned into a pandemic $[1,2]$. Globally, as of October 28,2020, there have been 43,540,030 confirmed 
cases of COVID-19, including 1,160,650 deaths (https:// covid19.who.int). Its clinical presentation varies widely, with some patients remaining asymptomatic while others develop acute respiratory distress syndrome (ARDS) and multiple organ failure [3].

Whereas the estimated case fatality rate of COVID-19 in the general population was initially between 3 and $4 \%$ [4], a recent meta-analysis showed an infection fatality rate with SARS-CoV-2 (which also includes mild or asymptomatic individuals) of $0.68 \%(0.53-0.82 \%)$ [5]. However, in hospitalized patients, mortality between 15 and $20 \%$ was observed, increasing to $40 \%$ in those patients needing ICU admission [6].

COVID-19 has also greatly affected nephrology practice. Severe COVID-19 infection may result in acute kidney injury (AKI), which is associated with increased mortality. On the other end of the spectrum, dialysis patients may be at higher risk for COVID-19 infection both due to the risk of cross-contamination in closed environments and due to abnormalities in the adaptive and innate immune systems. In addition, the prevalence of severe comorbidities such as cardiovascular disease, hypertension, and diabetes mellitus, which are associated with a higher risk of adverse outcome, is increased in the dialysis population.

This review focuses on the clinical aspects of dialysis patients with COVID-19 and on AKI in COVID-19 patients without prior kidney disease. This article will not focus on prevention of COVID-19 transmission within dialysis units, for which excellent recent reviews are available [7-9].

\section{Pathophysiology and Staging of COVID-19}

Severe COVID-19 infection can follow different stages. Stage I comprises the early infection phase with nonspecific symptoms such as fever, malaise, and dry cough; stage II concerns the pulmonary phase; and stage III concerns the hyperinflammation phase [10]. Whereas viral pathogenicity is most important in the pathogenesis of symptoms in the early stages of the disease, the host response increasingly takes over in the later stages. It has been suggested that these stages may have relevance for optimal therapy, with viral replication inhibitors being most important in the early stages and immunomodulators in the later stages of the disease [10]. From a pathophysiologic point of view, stage I is characterized by viral entry to the cell by adhesion of the viral spike protein to the angiotensin-converting enzyme 2 receptor (ACE2 re-

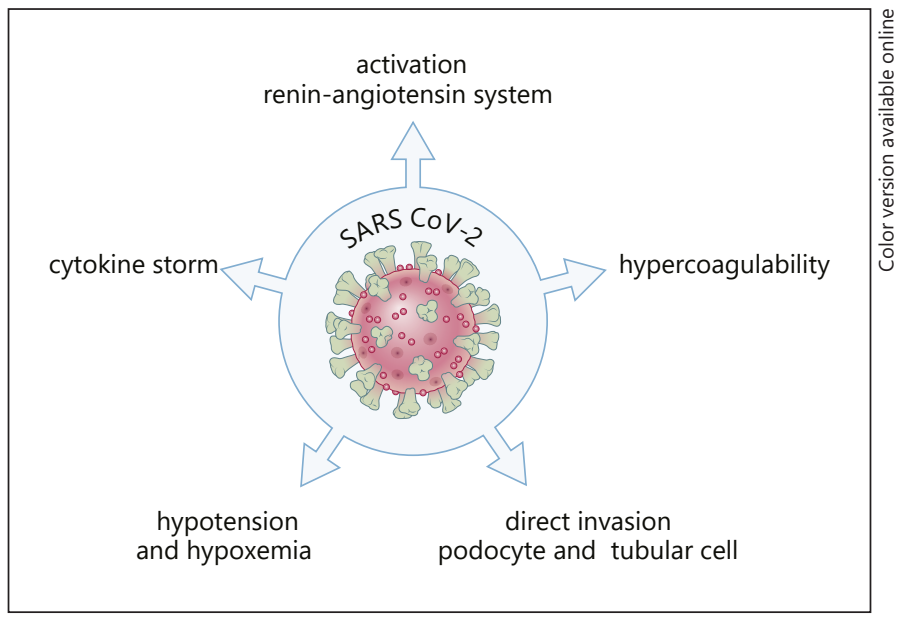

Fig. 1. Possible mechanisms behind the increased susceptibility of dialysis patients to SARS-CoV-2 infection. SARS-CoV-2, severe acute respiratory syndrome coronavirus 2 .

ceptor), following priming by cellular transmembrane serine protease 2 , which leads to viral replication and virus-induced tissue damage [11]. Although the predilection place is the respiratory tract, possibly given the abundant expression of ACE2 in airway cells, other organs, such as the kidney, which also has a high expression of ACE2, may be involved, as will be discussed later. In severe cases, endothelial cell damage (endotheliitis) by activation of macrophages and neutrophils and the complement system may follow, resulting in activation of the coagulation system [12]. Also, hyperactivation of the renin-angiotensin system may contribute to pathology in this stage $[11,13]$. Lastly, extensive activation of the innate immune system, with concomitant depletion of Tlymphocytes, may result in cytokine storm with clinical characteristics resembling hyperferritinemic syndromes like the hemophagocytic lymphohistiocytosis macrophage activation syndrome [14] (Fig. 1).

\section{COVID-19 in Dialysis Patients}

Several reports have described the clinical presentation, course, and outcome of patients on dialysis (Table 1). The earliest report from Wuhan found that 42 of 230 hemodialysis (HD) patients (18.3\%) and 4 out of 33 medical staff (12.2\%) were diagnosed with COVID-19. Thirteen HD patients, of whom 10 were definitely diagnosed with COVID-19, died (case mortality 23.8\%). Only 2 deaths were associated with respiratory failure, whereas 
Table 1. Incidence, clinical presentation, and outcome in dialysis patients with COVID-19 [15-33]

\begin{tabular}{|c|c|c|c|c|c|c|c|}
\hline Author & Patients & $\begin{array}{l}\text { Incidence, } \\
\%\end{array}$ & Symptoms & Diagnosis & $\begin{array}{l}\text { Admission, } \\
\%\end{array}$ & $\begin{array}{l}\text { ICU, } \\
\%\end{array}$ & $\begin{array}{l}\text { Mortality, } \\
\%\end{array}$ \\
\hline Ma et al. [15] & $42(230) \mathrm{HD}$ & 18.3 & Mild or no respiratory. Fever (13\%) & CT scan, RT-PCR & & 7.1 & 23.8 \\
\hline Xiong et al. [16] & $154(7,154)$ & 2.2 & $\begin{array}{l}\text { Fever }(52 \%) \text {, cough }(37 \%) \text {, } \\
\text { asymptomatic }(21 \%)\end{array}$ & CT scan, RT-PCR & & 27.5 & 31.3 \\
\hline Corbett et al. [17] & $300(1,530)$ & 19.6 & & RT-PCR & & & 20.3 \\
\hline La Milia et al. [19] & $25(209)$ & 12 & $\begin{array}{l}\text { 33/188 }(18 \%) \text { asymptomatic patients. } \\
\text { PCR positive }\end{array}$ & RT-PCR & $100^{\mathrm{a}}$ & & 52 \\
\hline Alberici et al. [21] & $94(643)$ & 15 & $\begin{array}{l}\text { All patients tested. } \\
18 / 94(20 \%) \text { asymptomatic }\end{array}$ & RT-PCR & 61 & & $\begin{array}{l}29(42 \text { in } \\
\text { hospitalized } \\
\text { patients })\end{array}$ \\
\hline Yau et al. [29] & $11(237)$ & 4.6 & $\begin{array}{l}\text { All patients tested. } \\
6 / 11(55 \%) \text { asymptomatic. Fever } \\
(9 \%) \text {, cough }(27 \%)\end{array}$ & RT-PCR & 45 & 18 & 0 \\
\hline Wang et al. [31] & $5(201)$ & 2.5 & $\begin{array}{l}\text { Diarrhoea }(80 \%) \text {, fever }(60 \%) \text {, } \\
\text { cough }(40 \%)\end{array}$ & CT scan, RT-PCR & $100^{\mathrm{a}}$ & 0 & 0 \\
\hline Quintaliani et al. [20] & $1,368(60.441)$ & 2.3 & & RT-PCR & & & 32.8 \\
\hline Manganaro et al. [22] & $130(5,793)$ & 2.2 & & RT-PCR & 74.6 & 30 & 24.6 \\
\hline Valeri et al. [24] & 53 & & $\begin{array}{l}\text { Fever ( } 49 \%) \text {, cough }(39 \%) \\
\text { dyspnoea }(36 \%)\end{array}$ & RT-CR & $100^{\mathrm{a}}$ & 14 & 31 \\
\hline Ng et al. [27] & 419 & & & & $100^{\mathrm{a}}$ & $\begin{array}{l}21 \\
\text { (mechanical } \\
\text { ventilation) }\end{array}$ & 31 \\
\hline Tortonese et al. [26] & 44 & & $\begin{array}{l}\text { Fever }(80 \%) \text {, dyspnoea }(30 \%) \\
\text { diarrhoea }(14 \%) \text {, cough }(43 \%)\end{array}$ & RT-PCR & 93 & 34 & 27.3 \\
\hline Creput et al. [33] & $38(200)$ & 19 & $\begin{array}{l}\text { All patients tested. } 11 \% \\
\text { asymptomatic. Fever }(68 \%) \text {, } \\
\text { cough }(63 \%)\end{array}$ & RT-PCR & 58 & 11 & 21 \\
\hline Jager et al. [28] & $\begin{array}{l}3,285(3,160 \mathrm{HD}, \\
125 \mathrm{PD})\end{array}$ & & & & & & 21 \\
\hline
\end{tabular}

CT, computed tomography; HD, hemodialysis; PD, peritoneal dialysis; RT-PCR; real-time polymerase chain reaction; ICU, intensive care unit. ${ }^{\text {a }}$ Cohort based on hospitalized patients. 
most patients died from hyperkalaemia, and cardiovascular or cerebrovascular causes. Except for 3 patients who needed admission to the ICU, most patients presented mild or no respiratory symptoms [15].

In a later study from the same city, 154 of the 7,154 HD patients (2.2\%) had laboratory-confirmed COVID-19. Whereas $21.4 \%$ of patients were asymptomatic over the whole course of the disease, $82 \%$ had radiological abnormalities, mainly ground-glass or patchy opacities [16]. Of the 131 patients who were available for further analysis, 101 were categorized as mild/moderate and 30 as severe or critical. At the end of the follow-up period, 41 patients (31\%) were deceased, whereas 41 patients still remained in hospital and 47 had been discharged. When the authors compared the characteristics of symptomatic and asymptomatic cases, a far higher prevalence of diabetes was observed in the symptomatic group, whereas the lymphocyte count was lower [16].

Corbett et al. [17], in greater London, reported that 300 out of 1,530 patients (19.6\%) developed COVID-19, when clustering in specific units and on specific shifts. The estimated reproduction number $\left(R_{\mathrm{o}}\right)$ was 2.2 , thus comparable to local epidemics in non-dialysis subjects. Nineteen patients with a previously negative outcome tested positive at a later stage (median 9 days later); $20.3 \%$ of the patients died, whereas $17 \%$ remained in the hospital at the end of follow-up. Apart from higher age, no specific risk factors for mortality were observed [17].

In a series from Japan, 99 dialysis patients were reported, of whom 16 (16.2\%) died, which was higher than the reported deaths in the general population (5.3\%), although the dialysis patients were also older. Follow-up with regard to mortality was not complete as some of the patients were still hospitalized at the time of publication [18]. Fever (defined as a body temperature $>37.5^{\circ} \mathrm{C}$ ) was reported in $95.1 \%$ and cough in $63.5 \%$ of patients who presented with computed tomography (CT) abnormalities typical for COVID-19 pneumonia.

In a single-centre report from Lecco, Italy, 55 out of 209 patients (26\%) tested positive for SARS-CoV-2. Thirty-three (18\%) patients were asymptomatic at the time of diagnosis. Thirteen out of 26 patients who needed to be hospitalized died (52\%), whereas $28 \%$ were discharged and $20 \%$ remained in the hospital at the end of follow-up. The infection fatality rate was $24 \%$ excluding those patients who were still hospitalized at the end of follow-up [19].

In a multiregional survey from Italy, the estimated proportion of SARS-CoV-2-positive patients was $2.26 \%$ (95\% CI 2.14-2.39), with large differences between re- gions. Infection was higher in HD patients - 3.55\% (CI $3.34-3.76$ ) as compared to $1.38 \%$ (CI 1.04-1.78) in peritoneal dialysis (PD) patients, suggesting that contagion in dialysis facilities may have played a role in the transmission of the disease. Case fatality rate was high, as 449 of 1,368 infected patients died (33\%), as compared to a case fatality rate of $13 \%$ in the general population [20].

The high mortality in HD patients with COVID-19 was also confirmed in other studies from different regions. In Brescia, Italy, 94 of $643 \mathrm{HD}$ patients (15\%) from 4 units tested positive. There were no major differences in incidence between 3 units which tested only symptomatic patients (14\%) versus the single unit which also tested asymptomatic patients/applied universal screening (16\%). In 13 of the 18 asymptomatic patients at diagnosis (72\%), chest X-ray was also negative. An overall mortality of $29 \%$ was observed [21]. In the Piedmont and Aosta regions of Northern Italy, the mortality rate in a cohort of 130 patients (which included both dialysis and transplanted patients) was $25 \%$. Mortality was higher in males and patients with a history of cardiovascular disease [22].

In a study from Spain in 36 HD patients, a mortality rate of $30.5 \%$ was noted during the observation period, whereas 7 out of 36 patients could be discharged [23]. Ischaemic heart disease, fever, older age ( $>70$ years), and dyspnoea at presentation were associated with the development of ARDS, while fever, cough, and a C-reactive protein higher than $50 \mathrm{mg} / \mathrm{L}$ at disease presentation were associated with an increased risk of death.

Another report from Wuhan compared 49 hospitalized patients with COVID-19 with age-matched controls. Ninety-two per cent of dialysis patients had compatible findings on CT scan, whereas lymphopenia $\left(\leq 1 \times 10^{9}\right)$ was observed in the great majority of patients. However, as compared to controls, the presence of fever (47 vs. $90 \%$ ) and cough (49 vs. $71 \%$ ) was lower. More patients on HD developed shock (16 vs. $4 \%$ ) or ARDS (20 vs. $6 \%$ ) or needed non-invasive or invasive ventilation (21 vs. $8 \%$ ). At the end of the follow-up, $14 \%$ of dialysis patients had died [34]. It should be noted that the mortality rate may even be higher in the reported series because the clinical course of the disease had not ended in all included patients. In a cohort of 59 hospitalized dialysis patients with COVID-19 (including 2 PD patients) from New York, the mortality rate was $31 \%$ in the overall group and $75 \%$ in those needing mechanical ventilation. At the time of presentation, fever was present in $49 \%$, cough in $39 \%$, and dyspnoea in $36 \%$ of cases [24]. A report from the COVIDIAL study from France reported on 1,234 patients with COVID-19. Fever was present in $57 \%$ of patients, 
cough in $69 \%$, and diarrhoea in $34 \%$. The case fatality rate was $24 \%$. Fever and CRP levels were independently associated with adverse outcomes [25]. In a study from a referral centre from the Paris region including 44 patients, the case fatality rate was $27 \%$. Cough, thrombopenia, increased lactate dehydrogenase, and CRP levels $>175 \mathrm{mg} /$ $\mathrm{dL}$ were associated with death in multivariate analysis [26].

In the largest cohort of hospitalized dialysis patients so far from the USA, 419 patients with ESRD were studied, with the great majority having chronic HD [27]. In-hospital death was 31 , and $22 \%$ needed mechanical ventilation. Risk factors for adverse outcome were, among others, age, lymphopenia, serum ferritin, and need for mechanical ventilation, whereas black race was associated with a reduced risk of death. Recent data from the EDTA Registry reported a crude mortality rate of $21.2 \%$ (attributable mortality 20.0\%) in 4,298 COVID-19 patients. Male gender and higher age were risk factors for mortality [28]. Lastly, in the very recently published ERACODA study, a COVID-19 attributable 28-day mortality of 25\% was observed in a cohort of 768 dialysis patients, of whom $70 \%$ were admitted to a hospital. Age and frailty were the most important risk factors for mortality [35].

Whereas the above-mentioned studies all suggest that dialysis patients have a higher risk of adverse outcomes, one study from Canada, in which universal screening was applied in the entire unit, showed more benign outcomes but also highlighted the risk of asymptomatic transmission. In this retrospective study of $237 \mathrm{HD}$ patients and 93 staff, $11(4.6 \%)$ patients and $11(12 \%)$ staff had a positive reverse transcription-polymerase chain reaction (RT-PCR) test for COVID-19 [29]. Among the test-positive individuals, $55 \%$ of HD patients and $55 \%$ of staff were asymptomatic, whereas $27 \%$ of dialysis patients and $36 \%$ of staff remained so during a mean follow-up time of 30 days. Five patients needed to be hospitalized, of which $2(18 \%)$ needed to be treated at an intensive care unit. None of the patients needed mechanical ventilation. A study from Spain which also applied universal screening in their 192 dialysis patients reported positive PCR results in 22 symptomatic and 14 asymptomatic patients. Nine of these 14 patients (i.e., $25 \%$ of the entire positive population) remained asymptomatic at the end of a 3-week follow-up. Shared transport, living in a nursing home, and previous hospitalization were risk factors for a positive test. Seven SARS-CoV-2 patients died during the follow-up [30]. The relatively high percentage of asymptomatic SARS-CoV-2-positive dialysis patients at the time of testing is in line with the experience in the general popu- lation. For example, when all passengers were tested during the outbreak at the Diamond Princess, $47 \%$ of the positively tested persons were asymptomatic at the time of diagnosis [36]. As an example, in a detailed clinical analysis of 5 dialysis patients, 3 presented with fever, 2 with dyspnoea, 4 with diarrhoea, and only 1 with dry cough, which fits with the description in other cohorts (Table 1). All had lymphocyte counts below 1.0 [31]. None of these patients developed severe respiratory insufficiency. All patients had abnormalities on CT scan, which was part of the screening procedure. However, in asymptomatic patients who tested positive for SARS-CoV-2, also radiographic abnormalities may be absent $[19,21]$.

In PD patients, evidence is more limited. In a cohort of 419 hospitalized patients with ESRD, 11 patients (2.6\%) were on chronic PD. Nine patients were discharged alive. Patients presented mainly with fever $(64 \%)$ and diarrhoea (55\%), whereas shortness of breath and cough were present in $45 \%$ at presentation. In $82 \%$ of patients, characteristic findings were present on chest X-ray [32].

Dialysis patients may not clear the virus easily [37]. In a cohort of 39 SARS-CoV-2-positive patients, by day 15 , $41 \%$ of patients had not yet cleared the virus, although no data on symptomatology were given. The authors recommended maintaining isolation of SARS-CoV-2-positive patients not until they are free of symptoms but until the virus is proven to be cleared.

Summarizing these results, the incidence of COVID-19 appears to be higher in dialysis units than in the background population, whereas the relative increase in incidence appears less pronounced in PD patients. Due to differences in case mix (in which either only symptomatic patients or also those diagnosed by universal screening were included) and as yet incomplete follow-up in many studies, the incidence and outcome vary widely in the literature. However, case mortality rates around 30\% in hospitalized or symptomatic patients are not unusual in the reports (Table 1). Still, the infection mortality rate is likely lower, given the fact that a significant proportion of SARS-CoV-2-positive dialysis patients may be asymptomatic. Thus, in general, despite an often insidious presentation, the case mortality rate in symptomatic dialysis patients appears to be high as compared to that in the general population.

Dialysis patients should therefore be considered a risk group, both in terms of infection risk and outcome [38]. Moreover, a high degree of clinical suspicion is needed as the clinical presentation in dialysis patients may be obscured because chronic dyspnoea is common in dialysis patients whereas the febrile response may be blunted [38] 
Still, in studies where universal screening was applied a significant proportion of dialysis patients was asymptomatic at the time of diagnosis by screening, and in this setting, a SARS-CoV-2 infection appears to be associated with a better prognosis.

\section{Why Are Dialysis Patients at Increased Risk for COVID-19 and Its Consequences?}

The question why dialysis patients show such an adverse prognosis with COVID-19 infection remains to be answered. Despite the fact that all HD patients were found to produce specific antibodies after COVID-19 [39], the response of the innate and adaptive immune systems to SARS-CoV-2 may be impaired to a larger degree in dialysis patients than in the general population. Natural killer cells, which form a first-line defense against SARS-CoV-2 [40], were found to be lower in dialysis patients than in controls in earlier studies [41]. The same holds true for naïve CD4+ and CD8+ T lymphocytes [42], which are also involved in the adaptive immune response to $\mathrm{CO}$ VID-19 [43, 44]. Moreover, the uremic state is accompanied by immunosenescence, characterized by chronic low-grade activation of the innate immune system, a reduction in the naïve $\mathrm{CD} 4+$ and $\mathrm{CD} 8+\mathrm{T}$-cell population with an increase in memory $\mathrm{T}$ cells with an inflammatory phenotype $[45,46]$, which might provide a background for a subsequent hyperinflammatory response [47]. In other words, it may be hypothesized that the inadequate initial viral clearance due to immunosenescence results in a subsequent hyperactivation of an already chronically stimulated innate immune system.

Dialysis patients are also often malnourished, which also can affect the function of the immune system [48]. Whether the reduced function of the innate and adaptive immune systems, in combination with a state of chronic activation of the innate immune system, increases the risk for COVID-19 infection and for severe complications in dialysis patients remains to be studied.

Next to this, COVID-19 is associated with severe endothelial damage [47], which may be even more severe in dialysis patients with their background of endothelial dysfunction. COVID-19 can also directly lead to cardiac damage, which is superimposed on an already compromised cardiac structure and function in dialysis patients [49]. Also, dialysis patients are often of older age, have severe comorbidity, and may suffer from pre-existent frailty. Whether these factors decrease their chance for acceptance to intensive care treatment cannot be deduced from the present literature, although in one report ICU admission was non-significantly lower (8\%) in dialysis patients than transplanted patients (21\%) [22]. On the other hand, in a large cohort of hospitalized patients, there was no difference in treatment with mechanical ventilation between patients with or without ESRD [27]. Summarizing, dialysis patients may be more susceptible for COVID-19 and its systemic consequences due to (1) an increased transmission risk; (2) a chronic activation but reduced functioning of the immune system; (3) a background of endothelial dysfunction; (4) damage to organs at a background of multi-organ pathology, with a reduced structural or functional reserve; and (5) pre-existent comorbidity and an increased risk of "system breakdown" due to their reduced functional and structural organ reserve [50] (Fig. 2).

\section{COVID-19 and AKI}

COVID patients without pre-existent kidney disease are also at risk for developing AKI. Whereas the risk initially appeared to be relatively low according to reports from earlier cohorts $[51,52]$, more recent studies have shown higher incidences of AKI. A meta-analysis of available studies showed an incidence of AKI in hospitalized patients with COVID-19 of 23\% (95\% CI 14-35\%) [13]. In another meta-analysis, a lower incidence was found (4.5\% [CI 3.0-6.0\%]) [53]. These differences are likely due to variations in the definition of AKI between different studies, the ongoing accumulation of evidence, and the inclusion of studies that have not yet appeared in peer-reviewed journals [13]. In an analysis of 2,626 patients from the New York area not yet included in metaanalyses, AKI, defined as an increase in serum $\mathrm{Cr}>0.3$ $\mathrm{mg} / \mathrm{dL}$ within $48 \mathrm{~h}$ or an increase $>1.5$ times vs. baseline, was present in $22.2 \%$ of patients, whereas $3.2 \%$ needed renal replacement therapy (RRT) [54]. The most recent study at the time of writing (September 15, 2020) included 3,993 hospitalized patients with COVID-19 also from the New York area, and observed an incidence of AKI of $46 \%$. Of the 1,835 patients with AKI, 19\% need dialysis. An in-hospital mortality of $50 \%$ was observed in those with AKI versus $8 \%$ in those patients without AKI, and 87 of the 832 patients who needed analysis were discharged alive. Of the 832 patients with AKI who were discharged from the hospital, $65 \%$ had recovery of AKI at the time of discharge [55].

The incidence of AKI is strongly related to the severity of the other COVID-19 symptomatology [56]. Whereas 
Fig. 2. Possible mechanisms behind COVID-19 and acute renal failure. SARS$\mathrm{CoV}-2$, severe acute respiratory syndrome coronavirus 2; NK, natural killer.

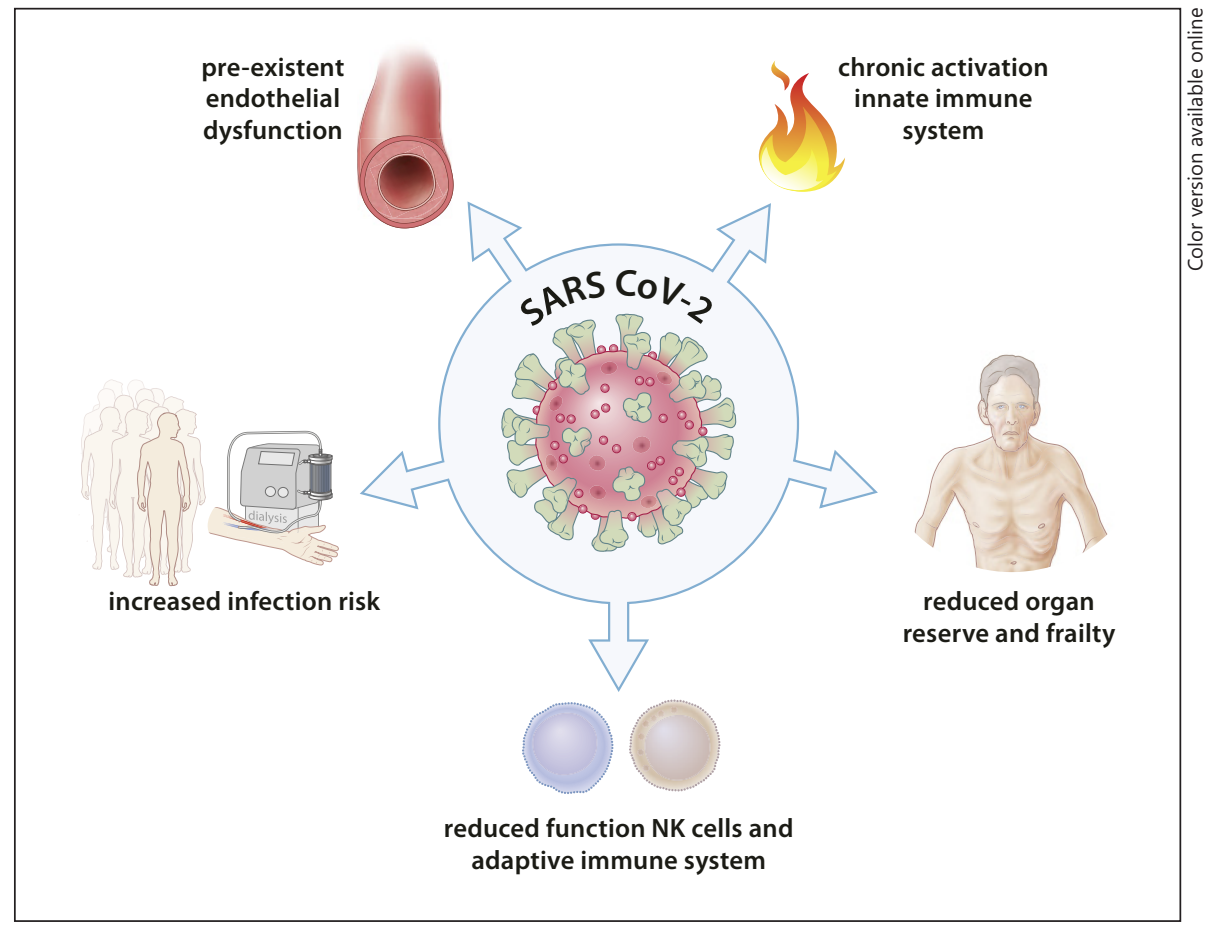

the incidence of AKI was $1.3 \%$ in mild cases, it increased to $36.4 \%$ in critical cases [53]. In the meta-analysis of Yang et al. [53], continuous renal replacement therapy (CRRT) was required in $5.6 \%$ of severe patients and $0.1 \%$ of non-severe patients. The presence of AKI in COVID-19 patients is of relevance as in an analysis of a cohort of 701 patients, AKI levels of stages 2 and higher were associated with an increased risk of mortality (HR 3.53 [1.5-8.27]) [57].

The need for RRT in critically ill patients with COVID-19 is associated with more severe outcomes [54]. Richardson et al. [54] found that of 225 patients treated with RRT, only $3(1.3 \%)$ were discharged alive from the hospital at the end of the follow-up, while 78 (34\%) had died, and $144(64 \%)$ were still in the hospital. In their meta-analysis, Yang et al. [53] reported that RRT was applied in $15.6 \%$ of non-survivors and $0.4 \%$ of survivors. In the largest study so far of 637 COVID-19 patients with RRT-dependent AKI, an in-hospital mortality of $63.3 \%$ was observed. Of the 216 discharged patients, $18.1 \%$ remained dialysis-dependent 60 days after ICU admission [58].

Also, proteinuria and hematuria are common in patients infected with COVID-19 [59]. In a meta-analysis, $57 \%$ of patients had proteinuria, which was classified as $2+$ or $3+$ in $10.6 \%$ of patients [53]. In a report from China, proteinuria and hematuria were both associated with increased mortality [57].

AKI in COVID-19 patients is most likely due to multiple mechanisms [60]. The first is invasion of the virus in the kidney, in which high ACE2 expression may play a role [61]. Next to this, dysregulation of the renin-angiotensin system, cytokine and complement activation, microvascular thrombosis, and general factors such as hypotension and hypoxemia can play a role in the pathogenesis of AKI in COVID-19 [13, 62].

SARS-CoV-2 particles were also found to be present in tubular epithelium and podocytes [63]. It has been suggested that the collapsing glomerulopathy which can be observed in COVID-19 is due to viral invasion of podocytes [64]. On the other hand, one study did not show any evidence of viral invasion in a group of 17 patients with renal manifestations and COVID-19 infections. Biopsies were performed because of AKI or nephrotic-range proteinuria. In this study, a mix of findings was observed, ranging from tubular injury to minimal change nephropathy, collapsing focal segmental glomerular sclerosis, but also membranous nephropathy and anti-glomerular basement membrane disease. In the last cases, it was hypothesized that damage to the alveolar capillary basement membrane could expose the Goodpasture antigen [65]. In another study by the same group, autopsy findings 
from 42 patients with AKI and COVID-19 infection were presented. In the majority of cases, evidence of acute tubular injury was observed. The difference between these 2 groups might be due to the specific indications for renal biopsy (such as a nephritic sediment or nephrotic-range proteinuria) as compared to the more general findings obtained by autopsy [66].

\section{Treatment of COVID-19 in ESRD}

Whereas treatment of severe COVID-19 is largely supportive with supplement oxygen treatment and prophylactic low-molecular-weight heparin, a large number of studies on more specific candidate treatments have been initiated. These can generally be divided into antiviral or immunomodulatory treatments [67]. Trials with agents initially proposed for treatment, such as (hydroxyl)chloroquine and lopinavir/ritonavir, have yielded largely negative results [6]. Whereas the progress in this field is very fast, at the time of writing, the most promising antiviral from randomized trails appears to be the antiviral agent remdesivir, a nucleoside analogue that inhibits viral RNA-dependent RNA polymerase. Although overall mortality did not change, a randomized controlled trial (RCT) including 1,063 patients reduced the median time of recovery from 15 to 11 days compared to placebo, although in another RCT no significant positive effects were observed [6]. Of note, no patients with ESRD were included in these trials. Dexamethasone $6 \mathrm{mg}$ daily reduced 28-day mortality in patients with supplementary oxygen ( 21.6 vs. $24.6 \%$ ) versus usual care, with the largest benefit observed in patients needing mechanical ventilation (29.3 vs. $41.4 \%$ ) [68]. Remdesivir and its metabolites are predominantly (74\%) renally eliminated, but especially the potential accumulation of its carrier sulphobutylether-B-cyclodextrin, which is also used by voriconazole, may be of relevance. Remdesivir and sulphobutylether-Bcyclodextrin are removed by RRT. Safety data on the use of remdesivir in kidney failure are scarce, and its use is generally contraindicated in patients with a $\mathrm{Cr}$ clearance below $30 \mathrm{~mL} / \mathrm{min}$. However, it has been suggested that after adequate information and consent of the patient, remdesivir could be used in patients with renal impairment for treatment of COVID-19 when the benefits are believed to outweigh the risks [69]. Of note, a recent study reported on the use of remdesivir in 16 patients with ESRD and 30 patients with AKI (of whom 25 were AKI stage 3 ). In this cohort, no severe elevations in liver enzymes or treatment attributable to decline in renal func- tion was observed. One patient experienced a hypersensitivity reaction during treatment [70].

The most promising immunomodulatory drugs for treatment at the time of writing, dexamethasone and the IL-6 inhibitor tocilizumab, may also be applied in patients with renal insufficiency [71, 72]. Of note, tocilizumab is not removed by conventional extracorporeal treatments [73].

Regarding dialysis treatment of patients with ESRD, great care must be applied to provide adequate dialysis given the fact that earlier reports showed that causes of death in COVID-19 were also related to possibly dialysisrelated factors such as cardiovascular complications of hyperkalaemia [15]. Still, logistic demands under exceptional circumstances have necessitated a reduction in dialysis frequency in combination with resins and diuretics [74]. In the setting of hospitalized PD patients, the number of exchanges can be reduced by application of automated peritoneal dialysis and, when possible, remote programming of treatment parameters [75].

\section{Some Specific Considerations for Extracorporeal Treatment in AKI}

In patients with $\mathrm{AKI}$, the indications to start RRTs are not different from the standard indications [76]. However, apart from the logistic demands and the need for adequate protection for the team, there are some specific technical considerations. Whereas excellent recommendations by expert panels for treatment of AKI in COVID-19 have been published recently [77, 78], we only focus shortly on some frequently occurring clinical dilemmas. The first is the increased thrombogenicity and heparin resistance associated with COVID-19. This can also have important implications for circuit patency. Helms et al. [79] reported circuit clotting in 28 of 29 patients on CRRT. When compared with matched non-COVID-19 intensive care unit patients, the number of filters needed per day was significantly higher in COVID-19 than non-COVID-19 patients (0.7 vs. 0.3 ). In this study, most patients had increased levels of D-dimers, fibrinogen, factor VIII, von Willebrand factor activity, and von Willebrand factor antigen, as well as positive lupus anticoagulant [79]. Al-Sarmkari et al. [80] reported repeated clotting of the CRRT circuit in 8 of 12 patients; although these patients were initially treated with prophylactic dose anticoagulation, after a change to therapeutic doses, 2 patients continued to experience repeated clotting. Short circuit survival times with conventional heparin 
dosing protocols were also reported by others [78]. High doses of heparin may be needed to get the activated partial thromboplastin time within the therapeutic range, possibly due to a difficulty to achieve adequate anti-X-a levels [81]. It has been suggested that also anti-X-a levels should be routinely monitored using unfractionated heparin [79]. Whereas many critically ill patients with COVID-19 may need systemic anticoagulation for thromboembolic complications, in our study, citrate coagulation with continuous venovenous hemodiafiltration provided in general excellent filter patency, even when frequent filter clotting occurred using systemic heparinization. Whereas there is no other specific preference between slow continuous HD and continuous venovenous hemofiltration or continuous venovenous hemodiafiltration, a potential advantage of the latter is that they can easily be combined with extracorporeal membrane oxygenation therapy [73].

PD may provide a reasonable alternative for $\mathrm{HD}$ or CRRT techniques, especially in case of logistic demands [82]. In order to reduce exposure of the nursing team, automated peritoneal dialysis may be preferred, when possible with remote patient monitoring software [75], although, on the other hand, it has been argued that CAPD may have the advantage of lesser catheter problems due to lower flow rates [83]. Severe COVID-19, in the face of rapid clinical deterioration, might be an indication for the use of hemoadsorption techniques, although results have only been presented in the form of case reports $[73,84$, 85] and clinical trials are awaited [76].

\section{Outlook and Conclusion}

COVID-19 has greatly affected many dialysis patients and has put great demands on dialysis facilities. Outbreaks have been curtailed by strict hygiene measures needed to limit transmission. Some authors have made a case for universal screening of the dialysis population. As this may put increased demands on limited resources, artificial intelligence might be of help in predicting which centres are at risk for imminent outbreaks [86]. A clinical dilemma is the fact that COVID-19 presents in many dialysis patients with relatively mild and unspecific symptoms, but the mortality, at least in symptomatic or hospitalized patients, is high. This necessitates a high degree of clinical suspicion. Subtle changes in clinical and laboratory parameters, which easily can go undetected in daily practice but which may be detected by artificial intelligence algorithms, may point to the development of COVID-19 [86]. In a recent study, a model was validated which predicted the development of COVID-19 within the next 3 days with an area under the receiver operating characteristics of 0.71 [86]. Whereas the mortality rate of COVID-19 is high in symptomatic dialysis patients, this should not lead to defeatism but rather to dedicated management while not withholding potentially life-saving interventions and ICU admission based on renal failure as a sole criterion.

For patients with AKI, mortality in patients needing RRT is very high, and there is an urgent need for improved treatment in these patients. Next to immunomodulatory drugs, possibly also adjuncts such as hemoadsorption might be of relevance in patients presenting with cytokine storm, although more evidence is needed. In the face of the ongoing pandemic, it is expected that the nephrology community will continue to play a major role in the fight and treatment against this disease. Rapid sharing of experiences and novel insights within the nephrology community will continue to be of insurmountable value for the treatment of our patients.

\section{Conflict of Interest Statement}

The authors have no conflict of interest to declare.

\section{Funding Sources}

There were no funding sources for this study.

\section{Author Contributions}

All authors contributed equally to this work.

References

1 Zhu N, Zhang D, Wang W, Li X, Yang B, Song $\mathrm{J}$, et al. A novel coronavirus from patients with pneumonia in China, 2019. N Engl J Med. 2020;382(8):727-33.

2 Lu R, Zhao X, Li J, Niu P, Yang B, Wu H, et al. Genomic characterisation and epidemiology of 2019 novel coronavirus: implications for virus origins and receptor binding. Lancet. 2020;395(10224):565-74.

3 Phua J, Weng L, Ling L, Egi M, Lim CM, Divatia JV, et al. Intensive care management of coronavirus disease 2019 (COVID-19): challenges and recommendations. Lancet Respir Med. 2020;8(5):506-17.

4 Rajgor DD, Lee MH, Archuleta S, Bagdasarian N, Quek SC. The many estimates of the COVID-19 case fatality rate. Lancet Infect Dis. 2020;20(7):776-7. 
5 Meyerowitz-Katz G, Merone L. A systematic review and meta-analysis of published research data on COVID-19 infection-fatality rates. Int J Infect Dis. 2020 Sep 29;101:138-8.

6 Wiersinga WJ, Rhodes A, Cheng AC, Peacock SJ, Prescott HC. Pathophysiology, transmission, diagnosis, and treatment of coronavirus disease 2019 (COVID-19): a review. JAMA. 2020 Aug 25;324(8):782-3.

7 Kliger AS, Silberzweig J. Mitigating risk of COVID-19 in dialysis facilities. Clin J Am Soc Nephrol. 2020;15(5):707-9.

8 Watnick S, McNamara E. On the frontline of the COVID-19 outbreak: keeping patients on long-term dialysis safe. Clin J Am Soc Nephrol. 2020;15(5):710-3.

9 Basile C, Combe C, Pizzarelli F, Covic A, Davenport A, Kanbay M, et al. Recommendations for the prevention, mitigation and containment of the emerging SARS-CoV-2 (COVID-19) pandemic in haemodialysis centres. Nephrol Dial Transplant. 2020;35(5):737-41.

10 Siddiqi HK, Mehra MR. COVID-19 illness in native and immunosuppressed states: a clinical-therapeutic staging proposal. J Heart Lung Transplant. 2020;39(5):405-7.

11 Gupta A, Madhavan MV, Sehgal K, Nair N, Mahajan S, Sehrawat TS, et al. Extrapulmonary manifestations of COVID-19. Nat Med. 2020;26(7):1017-32.

12 Noris M, Benigni A, Remuzzi G. The case of complement activation in COVID-19 multiorgan impact. Kidney Int. 2020;98(2):314-22.

13 Gabarre P, Dumas G, Dupont T, Darmon M, Azoulay E, Zafrani L. Acute kidney injury in critically ill patients with COVID-19. Intensive Care Med. 2020;46(7):1339-48.

14 Shoenfeld Y. Corona (COVID-19) time musings: our involvement in COVID-19 pathogenesis, diagnosis, treatment and vaccine planning. Autoimmunity Rev. 2020;19(6): 102538.

15 Ma Y, Diao B, Lv X, Zhu J, Liang W, Liu L, et al. COVID-19 in hemodialysis (HD) patients: report from one HD center in Wuhan, China. medRxiv. 2020:2020.02.24.20027201.

16 Xiong F, Tang H, Liu L, Tu C, Tian JB, Lei CT, et al. Clinical characteristics of and medical interventions for COVID-19 in hemodialysis patients in Wuhan, China. J Am Soc Nephrol. 2020;31(7):1387-97.

17 Corbett RW, Blakey S, Nitsch D, Loucaidou M, McLean A, Duncan N, et al. Epidemiology of COVID-19 in an urban dialysis center. J Am Soc Nephrol. 2020;31(8):1815-23.

18 COVID-19 Task Force Committee of the Japanese Association of Dialysis Physicians; Japanese Society for Dialysis Therapy; Japanese Society of Nephrology; Kikuchi K, Nangaku M, Ryuzaki M, et al. COVID-19 of dialysis patients in Japan: current status and guidance on preventive measures. Ther Apher Dial. 2020;24(4):361-5.

19 La Milia V, Bacchini G, Bigi MC, Casartelli D, Cavalli A, Corti M, et al. COVID-19 outbreak in a large hemodialysis center in Lombardy, Italy. Kidney Int Rep. 2020;5(7):1095-9.
20 Quintaliani G, Reboldi G, Di Napoli A, Nordio M, Limido A, Aucella F, et al. Exposure to novel coronavirus in patients on renal replacement therapy during the exponential phase of COVID-19 pandemic: survey of the Italian Society of Nephrology. J Nephrol. 2020;33(4):725-36.

21 Alberici F, Delbarba E, Manenti C, Econimo L, Valerio F, Pola A, et al. A report from the Brescia Renal COVID Task Force on the clinical characteristics and short-term outcome of hemodialysis patients with SARS-CoV-2 infection. Kidney Int. 2020;98(1):20-6.

22 Manganaro M, Baldovino S; Working group of the P, Aosta Valley Section of the SIN. First considerations on the SARS-CoV-2 epidemic in the Dialysis Units of Piedmont and Aosta Valley, Northern Italy. J Nephrol. 2020;33(3): 393-5.

23 Goicoechea M, Sánchez Cámara LA, Macías N, Muñoz de Morales A, Rojas ÁG, Bascuñana A, et al. COVID-19: clinical course and outcomes of 36 hemodialysis patients in Spain. Kidney Int. 2020;98(1):27-34.

24 Valeri AM, Robbins-Juarez SY, Stevens JS, Ahn W, Rao MK, Radhakrishnan J, et al. Presentation and outcomes of patients with ESKD and COVID-19. J Am Soc Nephrol. 2020;31(7):1409-15.

25 Keller N, Chantrel F, Krummel T, Bazin-Kara D, Faller AL, Muller C, et al. Impact of firstwave COronaVIrus disease 2019 infection in patients on haemoDIALysis in Alsace: the observational COVIDIAL study. Nephrol Dial Transplant. 2020;35(8):1338-411.

26 Tortonese S, Scriabine I, Anjou L, Loens C, Michon A, Benabdelhak M, et al. COVID-19 in patients on maintenance dialysis in the Paris region. Kidney Int Rep. 2020;5(9):1535-44.

$27 \mathrm{Ng} \mathrm{JH}$, Hirsch JS, Wanchoo R, Sachdeva M, Sakhiya V, Hong S, et al. Outcomes of patients with end-stage kidney disease hospitalized with COVID-19. Kidney Int. 2020 Aug 15; S0085-2538(20):30945-5.

28 Jager KJ, Kramer A, Chesnaye NC, Couchoud C, Sanchez-Alvarez JE, Garneata L, et al. Results from the ERA-EDTA Registry indicate a high mortality due to COVID-19 in dialysis patients and kidney transplant recipients across Europe. Kidney Int. 2020 Oct 15; S0085-2538(20):31081-4.

29 Yau K, Muller MP, Lin M, Siddiqui N, Neskovic S, Shokar G, et al. COVID-19 outbreak in an urban hemodialysis unit. Am J Kidney Dis. 2020 Nov;76(5):690-5.e1.

30 Rincon A, Moreso F, Lopez-Herradon A, Fernandez-Robres MA, Cidraque I, Nin J, et al. The keys to control a COVID-19 outbreak in a haemodialysis unit. Clin Kidney J. 2020; 13(4):542-9.

31 Wang R, Liao C, He H, Hu C, Wei Z, Hong Z, et al. COVID-19 in hemodialysis patients: a report of 5 cases. Am J Kidney Dis. 2020; $76(1): 141-3$.
32 Sachdeva M, Uppal NN, Hirsch JS, Ng JH, Malieckal D, Fishbane S, et al. COVID-19 in hospitalized patients on chronic peritoneal dialysis: a case series. Am J Nephrol. 2020; 51(8):669-74.

33 Creput C, Fumeron C, Toledano D, Diaconita $\mathrm{M}$, Izzedine H. COVID-19 in patients undergoing hemodialysis: prevalence and asymptomatic screening during a period of high community prevalence in a Large Paris Center. Kidney Med. 2020 Oct 22.

$34 \mathrm{Wu}$ J, Li J, Zhu G, Zhang Y, Bi Z, Yu Y, et al. Clinical features of maintenance hemodialysis patients with 2019 novel coronavirus-infected pneumonia in Wuhan, China. Clin J Am Soc Nephrol. 2020 Aug 7;15(8):1139-45.

35 Hilbrands LB, Duivenvoorden R, Vart P, Franssen CFM, Hemmelder MH, Jager KJ, et al., ERACODA Collaborators.. COVID19-related mortality in kidney transplant and dialysis patients: results of the ERACODA collaboration. Nephrol Dial Transplant. 2020 Nov;35(11): 1973-83.

36 Oran DP, Topol EJ. Prevalence of asymptomatic SARS-CoV-2 infection: a narrative review. Ann Intern Med. 2020 Sep;173(5):3627.

37 Dudreuilh C, Kumar N, Moxham V, Hemsley C, Goldenberg S, Moutzouris DA. De-isolation of COVID-19-positive hemodialysis patients in the outpatient setting: a single-center experience. Kidney Int. 2020;98(1):236-7.

38 Ikizler TA. COVID-19 in dialysis patients: adding a few more pieces to the puzzle. Kidney Int. 2020;98(1):17-9.

39 De Vriese AS, Reynders M. IgG Antibody response to SARS-CoV-2 infection and viral RNA persistence in patients on maintenance hemodialysis. Am J Kidney Dis. 2020 Sep; 76(3):440-1.

40 Vabret N, Britton GJ, Gruber C, Hegde S, Kim J, Kuksin M, et al. Immunology of COVID-19: current state of the science. Immunity. 2020; 52(6):910-41.

41 Peraldi MN, Berrou J, Métivier F, Toubert A. Natural killer cell dysfunction in uremia: the role of oxidative stress and the effects of dialysis. Blood Purif. 2013;35(Suppl 2):14-9.

42 Chiu YL, Shu KH, Yang FJ, Chou TY, Chen PM, Lay FY, et al. A comprehensive characterization of aggravated aging-related changes in T lymphocytes and monocytes in endstage renal disease: the iESRD study. Immun Ageing. 2018;15:27.

43 Azkur AK, Akdis M, Azkur D, Sokolowska M, van de Veen $\mathrm{W}$, Brüggen $\mathrm{MC}$, et al. Immune response to SARS-CoV-2 and mechanisms of immunopathological changes in COVID-19. Allergy. 2020;75(7):1564-81.

44 Cunha LL, Perazzio SF, Azzi J, Cravedi P, Riella LV. Remodeling of the immune response with aging: immunosenescence and its potential impact on COVID-19 immune response. Front Immunol. 2020;11:1748.

45 Betjes MG. Uremia-associated ageing of the thymus and adaptive immune responses. Toxins. 2020;12(4):224. 
46 Kooman JP, Dekker MJ, Usvyat LA, Kotanko $\mathrm{P}$, van der Sande FM, Schalkwijk CG, et al. Inflammation and premature aging in advanced chronic kidney disease. Am J Physiol Renal Physiol. 2017;313(4):F938-50.

47 Korakas E, Ikonomidis I, Kousathana F, Balampanis K, Kountouri A, Raptis A, et al. Obesity and COVID-19: immune and metabolic derangement as a possible link to adverse clinical outcomes. Am J Physiol Endocrinol Metab. 2020;319(1):E105-9.

48 Bencivenga L, Rengo G, Varricchi G. Elderly at time of COronaVIrus disease 2019 (COVID-19): possible role of immunosenescence and malnutrition. Geroscience. 2020;42(4): 1089-92.

49 Akhmerov A, Marbán E. COVID-19 and the heart. Circ Res. 2020;126(10):1443-55.

50 Kooman JP, Broers NJ, Usvyat L, Thijssen S, van der Sande FM, Cornelis T, et al. Out of control: accelerated aging in uremia. Nephrol Dial Transplant. 2013;28(1):48-54.

51 Guan WJ, Ni ZY, Hu Y, Liang WH, Ou CQ, $\mathrm{He}$ JX, et al. Clinical characteristics of coronavirus disease 2019 in China. N Engl J Med. 2020;382(18):1708-20.

52 Wang L, Li X, Chen H, Yan S, Li D, Li Y, et al. Coronavirus disease 19 infection does not result in acute kidney injury: an analysis of 116 hospitalized patients from Wuhan, China. Am J Nephrol. 2020;51(5):343-8.

53 Yang X, Jin Y, Li R, Zhang Z, Sun R, Chen D. Prevalence and impact of acute renal impairment on COVID-19: a systematic review and meta-analysis. Crit Care. 2020; 24(1):356.

54 Richardson S, Hirsch JS, Narasimhan M, Crawford JM, McGinn T, Davidson KW, et al. Presenting characteristics, comorbidities, and outcomes among 5700 patients hospitalized with COVID-19 in the New York city area. JAMA. 2020 May 26;323(20):2052-9.

55 Chan L, Chaudhary K, Saha A, Chauhan K, Vaid A, Zhao S, et al. AKI in hospitalized patients with COVID-19. J Am Soc Nephrol. 2020 Sep 3:ASN.2020050615.

56 Sun DQ, Wang TY, Zheng KI, Targher G, Byrne CD, Chen YP, et al. Subclinical acute kidney injury in COVID-19 patients: a retrospective cohort study. Nephron. 2020;144(7):34750.

57 Cheng Y, Luo R, Wang K, Zhang M, Wang Z, Dong $\mathrm{L}$, et al. Kidney disease is associated with in-hospital death of patients with COVID-19. Kidney Int. 2020;97(5):829-38.

58 Gupta S, Coca SG, Chan L, Melamed ML, Brenner SK, Hayek SS, et al. AKI treated with renal replacement therapy in critically ill patients with COVID-19. J Am Soc Nephrol. 2020 Oct 16:ASN.2020060897.

59 Hong D, Long L, Wang AY, Lei Y, Tang Y, Zhao JW, et al. Kidney manifestations of mild, moderate and severe coronavirus disease 2019: a retrospective cohort study. Clin Kidney J. 2020;13(3):340-6.
60 Gagliardi I, Patella G, Michael A, Serra R, Provenzano M, Andreucci M. COVID-19 and the kidney: from epidemiology to clinical practice. J Clin Med. 2020;9(8):2506.

61 Perico L, Benigni A, Remuzzi G. Should COVID-19 concern nephrologists? Why and to what extent? The emerging impasse of angiotensin blockade. Nephron. 2020;144(5):21321.

62 Batlle D, Soler MJ, Sparks MA, Hiremath S, South AM, Welling PA, et al. Acute kidney injury in COVID-19: emerging evidence of a distinct pathophysiology. J Am Soc Nephrol. 2020;31(7):1380-3.

63 Su H, Yang M, Wan C, Yi LX, Tang F, Zhu HY, et al. Renal histopathological analysis of 26 postmortem findings of patients with $\mathrm{CO}$ VID-19 in China. Kidney Int. 2020;98(1): 219-27.

64 Kissling S, Rotman S, Gerber C, Halfon M, Lamoth F, Comte D, et al. Collapsing glomerulopathy in a COVID-19 patient. Kidney Int. 2020;98(1):228-31.

65 Kudose S, Batal I, Santoriello D, Xu K, Barasch J, Peleg Y, et al. Kidney biopsy findings in patients with COVID-19. J Am Soc Nephrol. 2020 Sep;31(9):1959-68.

66 Santoriello D, Khairallah P, Bomback AS, Xu K, Kudose S, Batal I, et al. Postmortem kidney pathology findings in patients with COVID-19. J Am Soc Nephrol. 2020 Sep;31(9): 2158-67.

67 Pascarella G, Strumia A, Piliego C, Bruno F, Del Buono R, Costa F, et al. COVID-19 diagnosis and management: a comprehensive review. J Intern Med. 2020;288(2):192-206.

68 Group RC, Horby P, Lim WS, Emberson JR, Mafham M, Bell JL, et al. Dexamethasone in hospitalized patients with covid-19: preliminary report. N Engl J Med. 2020 Jul 17:NEJMoa2021436.

69 Adamsick ML, Gandhi RG, Bidell MR, Elshaboury RH, Bhattacharyya RP, Kim AY, et al. Remdesivir in patients with acute or chronic kidney disease and COVID-19. J Am Soc Nephrol. 2020;31(7):1384-6.

70 Thakare S, Gandhi C, Modi T, Bose S, Deb S, Saxena N, et al. Safety of remdesivir in patients with acute or chronic kidney disease. Kidney Int Rep. 2020 Oct 10.

71 Mori S, Yoshitama T, Hidaka T, Hirakata N, Ueki Y. Effectiveness and safety of tocilizum$a b$ therapy for patients with rheumatoid arthritis and renal insufficiency: a real-life registry study in Japan (the ACTRA-RI study). Ann Rheum Dis. 2015;74(3):627-30.

72 Iwamoto M, Honma S, Asano Y, Minota S. Effective and safe administration of tocilizumab to a patient with rheumatoid arthritis on haemodialysis. Rheumatol Int. 2011;31(4): $559-60$.

73 Ronco C, Reis T, Husain-Syed F. Management of acute kidney injury in patients with COVID-19. Lancet Respir Med. 2020;8(7): 738-42.
74 Fisher M, Yunes M, Mokrzycki MH, Golestaneh L, Alahiri E, Coco M. Chronic hemodialysis patients hospitalized with COVID-19: short-term outcomes in Bronx. New York: Kidney360; 2020.

75 Parapiboon W, Ponce D, Cullis B. Acute peritoneal dialysis in COVID-19. Perit Dial Int. 2020;40(4):359-62.

76 Clark EG, Hiremath S, Soroka SD, Wald R, Weir MA. CSN COVID-19 rapid review program: management of acute kidney injury. Can J Kidney Health Dis. 2020;7: 2054358120941679.

77 Ronco C, Bagshaw SM, Bellomo R, Clark WR, Husain-Syed F, Kellum JA, et al. Extracorporeal blood purification and organ support in the critically ill patient during COVID-19 pandemic: expert review and recommendation. Blood Purif. 2020 May 26:1-11.

78 Nadim MK, Forni LG, Mehta RL, Connor MJ Jr, Liu KD, Ostermann M, et al. COVID19-associated acute kidney injury: consensus report of the 25th Acute Disease Quality Initiative (ADQI) Workgroup. Nat Rev Nephrol. 2020 Dec;16(12):747-64.

79 Helms J, Tacquard C, Severac F, Leonard-Lorant I, Ohana M, Delabranche X, et al. High risk of thrombosis in patients with severe SARS-CoV-2 infection: a multicenter prospective cohort study. Intensive Care Med. 2020;46(6):1089-98.

80 Al-Samkari H, Karp Leaf RS, Dzik WH, Carlson JCT, Fogerty AE, Waheed A, et al. COVID-19 and coagulation: bleeding and thrombotic manifestations of SARS-CoV-2 infection. Blood. 2020;136(4):489-500.

81 Dutt T, Simcox D, Downey C, McLenaghan D, King C, Gautam M, et al. Thromboprophylaxis in COVID-19: anti-FXa-the missing factor? Am J Respir Crit Care Med. 2020;202(3): 455-7.

82 Ponce D, Balbi AL, Durand JB, Moretta G, Divino-Filho JC. Acute peritoneal dialysis in the treatment of COVID-19-related acute kidney injury. Clin Kidney J. 2020;13(3):26973.

83 Wilkie M, Davies S. Peritoneal dialysis in the time of COVID-19. Perit Dial Int. 2020;40(4): 357-8.

84 Esmaeili Vardanjani A, Ronco C, Rafiei H, Golitaleb M, Pishvaei MH, Mohammadi M. Early hemoperfusion for cytokine removal may contribute to prevention of intubation in patients infected with COVID-19. Blood Purif. 2020 Jun 26:1-4.

85 Dastan F, Saffaei A, Mortazavi SM, Jamaati H, Adnani N, Samiee Roudi S, et al. Continues renal replacement therapy (CRRT) with disposable hemoperfusion cartridge: a promising option for severe COVID-19. J Glob Antimicrob Resist. 2020;21:340-1.

86 Monaghan C, Larkin JW, Chaudhuri S, Han $\mathrm{H}$, Jiao Y, Bermudez KM, et al. Artificial intelligence for COVID-19 risk classification in kidney disease: can technology unmask an unseen disease? medRxiv. 2020:2020.06.15. 20131680. 